\title{
ESTUDIOS
}

\section{Gracias a la vida, Trío para \\ un nuevo tiempo y el tercer perído compositivo de Celso Garrido-Lecca}

\author{
Gracias a la vida, Trío para un nuevo tiempo, \\ and Celso Garrido-Lecca's Third Compositional Period
}

\author{
por \\ Nelson Niño Vásquez \\ Pontificia Universidad Católica de Valparaíso \\ nelson.nino@ucv.cl
}

\begin{abstract}
Celso Garrido-Lecca divide su producción musical en tres grandes períodos. El Trío para un Nuevo Tiempo fue compuesto en 1985 para un trío clásico (violín, violonchelo y piano). Marca el inicio de su tercer período compositivo, fase en la que él logra sintetizar toda su vasta experiencia como compositor. A lo largo de los tres movimientos de este trío es posible encontrar variadas influencias musicales, incluyendo citas de Gracias a la vida (1966) de Violeta Parra en el segundo movimiento, así como también claras referencias a melodías andinas en el tercero. El inicio de esta nueva etapa en la carrera compositiva de Celso Garrido-Lecca se caracteriza además por la creación de un acorde original de cuatro alturas, el cual llegó a convertirse en un importante recurso tanto armónico como melódico en muchas de las obras que le sucedieron. En este artículo se analiza el Trío para un nuevo tiempo, con un especial énfasis en todas las posibles conexiones entre esta obra y la canción de Violeta Parra. El acorde de cuatro alturas establecido por Garrido-Lecca en 1985, así como otros elementos musicales que caracterizan su tercer período compositivo, son examinados en detalle.
\end{abstract}

Palabras clave: Violeta Parra, Alexander Scriabin, Nueva Canción Chilena, acorde místico, tritono.

Celso Garrido-Lecca himself divided his musical output into three major periods. Trío para un Nuevo Tiempo was composed in 1985 for the traditional piano trio made up of violin, violoncello and piano. It marked the beginning of his third compositional period, in which he sought to synthesize his vast previous experience as a composer. The three movements of this Trio display various musical influences, including the use of Violeta Parra's song Gracias a la vida (1966) as a seminal theme for the second movement and the quotation of Andean melodies in the third movement. As part of this new phase in his career this Trio also presents an original chord of four pitches, which becomes an important source of harmonic and melodic material in many of the works that ensued. In this article the Trí para un Nuevo Tiempo will be analyzed highlighting the possible connections between this particular work and Violeta Parra's song Gracias a la vida. The chord of four pitches devised by Garrido-Lecca in 1985 as well as other musical elements that characterize his third compositional period will also be examined in detail.

Key words: Violeta Parra, Alexander Scriabin, Nueva Canción Chilena, mystic chord, tritone. 
Celso Garrido-Lecca Seminario nació en Piura, Perú, el 9 de marzo de 1926르. En mayo de 1950 viajó a Santiago de Chile gracias a una beca ofrecida por Domingo Santa Cruz con el objeto de continuar sus estudios de composición en el entonces Conservatorio Nacional de la Universidad de Chile, ciudad en la que permaneció hasta el 4 de noviembre de $1973^{2}$. El propio Garrido-Lecca ha dividido su producción musical en tres grandes períodos. El primero de ellos comprende las obras compuestas en Chile entre 1953 y 1973 en las que se advierten claras influencias del serialismo vienés, técnica aprendida de su maestro Frederick (Fré) Focke. Su segundo período compositivo abarca las obras compuestas entre 1974 y 1984, las cuales se caracterizan por un marcado predominio de elementos musicales folclóricos y populares de la región andina. El tercer período, de síntesis, se inició en 1985 con la composición de Trío para un nuevo tiempoy se extiende hasta el presente. En esta última fase compositiva Garrido-Lecca ha sido capaz de sintetizar todas sus experiencias musicales previas en una propuesta musical única. Se advierte el sincretismo de técnicas compositivas contemporáneas junto a elementos musicales provenientes de la tradición andina y de la Nueva Canción latinoamericana. Algunas obras importantes de este período son Trío para un nuevo tiempo (1985), Cuarteto de cuerdas N ${ }^{\circ} 2$ (1987), Concierto para violonchelo y orquesta (1989), Concierto para guitarra y cuatro grupos instrumentales (1990), Dúo concertante para charango y guitarra (1991) y Sinfonía No 2 (2000).

\section{EL CONCEPTO DE “NUEVO TIEMPO”}

Durante el período que dirigió el Conservatorio Nacional de Lima (1976-79), Garrido-Lecca se encargó de promover el aprendizaje de instrumentos nativos al interior de esta institución, y creó además una serie de conjuntos musicales basados en el modelo de grupos chilenos como Quilapayún e Inti-Illimani. Uno de estos grupos recibió el nombre de "Tiempo Nuevo". Mediante este calificativo el compositor deseaba expresar la necesidad de un "nuevo tiempo" de integración entre las músicas doctas y populares sobre la base del estudio de los instrumentos nativos sudamericanos. Algunos años más tarde Garrido-Lecca volvería a utilizar este mismo concepto, pero en relación con un trío clásico, fuertemente conectado con la tradición musical occidental.

Luis Merino Montero señala que Garrido-Lecca planeaba enfatizar en el Trío para un nuevo tiempo (1985) uno de sus más grandes anhelos: acortar la distancia entre la música docta y la música popular urbana por medio de la Nueva Canción

1 Antecedentes biográficos acerca del compositor se encuentran disponibles en Torres 1999: 525-528; Tello 2001a: 9-12; Iturriaga 2001: 549-550; Niño 2011: 12-28.

2 Un acuerdo entre los conservatorios nacionales de Perú y Chile permitieron a Armando Sánchez -hijo de Carlos Sánchez Málaga, director del Conservatorio Nacional de Lima- y a Celso Garrido-Lecca viajar a Santiago de Chile en mayo de 1950. Santa Cruz define a Garrido-Lecca como un joven y talentoso compositor que se integró de manera notable a la vida musical chilena. Residió en el país por más de veinte años y llegó a ser presidente de la Asociación Nacional de Compositores desde su condición de compositor peruano-chileno. Ver Santa Cruz 2007: 854. 
latinoamericana. Merino basó sus comentarios en una carta que le enviara el compositor el 14 de julio de 1999, en cuyas líneas Garrido-Lecca establecía claramente su deseo de integración de "ambas orillas", la culta y la popular. En la misma misiva el compositor agregaba que Trío para un nuevo tiempo (1985) constituía una antítesis al Cuarteto para el fin de los tiempos de Messiaen (1940-1941), obra que representaba una mirada pesimista del futuro de la humanidad hecha desde una Europa en crisis $^{3}$. En este mismo sentido, Enrique Iturriaga comenta que mediante el título de esta obra el compositor logra materializar con precisión sus propósitos estéticos de un nuevo tiempo de síntesis, unidad y hermandad para Latinoamérica. Agrega que esta pieza constituye también el inicio de una nueva etapa en la carrera compositiva de Garrido-Lecca ${ }^{4}$.

Una de las características centrales del Trío para un nuevo tiempo (1985) es la cita que hace el compositor de la canción Gracias a la vida, compuesta por Violeta Parra en 1966. Garrido-Lecca comenta que escogió esta canción no solo por su valor estético y por constituir un ícono de la música popular chilena, sino también por poseer ciertas características musicales que le resultaban interesantes de desarrollar por medio de este trío.

\section{GRACIAS A LA VIDA DE VIOLETA PARRA}

En octubre de 1960 Violeta Parra comenzó una relación sentimental con el antropólogo suizo Gilbert Favré, quien era dieciocho años menor que ella ${ }^{5}$. En 1961 ambos viajaron a París y decidieron permanecer allí por cuatro años, período durante el cual Favré aprendió a interpretar varios instrumentos musicales con ayuda de Violeta, hasta que se convirtió en un virtuoso ejecutante de quena. Luego de su regreso a Santiago de Chile en 1965 la relación entre ambos llegó a su fin. El antropólogo suizo partió rumbo a Bolivia y Violeta cayó en una profunda crisis

3 Merino 2003: 48. El halo pesimista de esta obra se debe principalmente a que el Cuarteto para el fin de los tiempos fue compuesto y estrenado por Olivier Messiaen en el campo de prisioneros de guerra alemán Stalag VIIIA, en Görlitz, Silesia, durante la Segunda Guerra Mundial. Esta obra de cámara, compuesta para violín, clarinete en Sib, violonchelo y piano, fue estrenada el 15 de enero de 1941 en instrumentos musicales que se encontraban en un deplorable estado de conservación y ante unos cinco mil espectadores, según testimonio del propio Messiaen. Un completo análisis musical de los ocho movimientos que componen esta obra se encuentra disponible en Pople 1998: 17-87. La historia de este cuarteto, construida principalmente por medio de testimonios de los músicos participantes y de algunos espectadores que presenciaron su estreno, se encuentra disponible en Rischin 2003: 1-100.

4 Comentarios extraídos de la carátula del disco compacto Encuentros de Celso GarridoLecca, producido en 1995 por Manuel Garrido-Lecca y cofinanciado por la Occidental Petroleum Corporation del Perú.

5 Favré, quien tocaba el clarinete, llegó a Chile con un grupo de arqueólogos dirigidos por Jean Christian Spani. Motivado por un interés personal en la música folclórica, quiso conocer a los mejores intérpretes chilenos. Varios artistas en la Universidad de Chile le sugirieron los nombres de Margot Loyola y Violeta Parra. Finalmente la artista Adela Gallo invitó a Favré a visitar a Violeta Parra en el día de su cumpleaños. Ver Sáez 1999: 119. 
emocional que la llevó a atentar contra su propia vida el 14 de enero de $1966^{6}$. A mediados de diciembre de ese mismo año Favré viajó a Santiago de Chile junto a su grupo musical Los Jairas, con el fin de participar en un festival folclórico que tuvo lugar en el Teatro Caupolicán. En dicha ocasión el antropólogo suizo anunció públicamente su boda con una joven de nacionalidad boliviana, noticia que caló profundamente en Violeta Parra 7 .

Las canciones compuestas por Violeta Parra durante el año 1966 ciertamente reflejan su convulsionado estado emocional, canciones que forman parte del histórico álbum publicado por ella hacia fines de ese mismo año. Luego de una larga relación comercial con el sello discográfico Odeón, Violeta Parra decidió producir su último álbum bajo un nuevo sello, RCA, el cual contempló la participación de sus hijos Isabel y Ángel, y el músico uruguayo Alberto Zapicán ${ }^{8}$.

Este álbum recibió el nombre de "Las últimas composiciones de Violeta Parra", un título que nos estimula a una doble interpretación. Comenzó a ser distribuido comercialmente a mediados del mes de enero de 1967 y la propia Violeta tuvo oportunidad de vender varios ejemplares durante sus últimas presentaciones 9 . Este fonograma de larga duración se convertiría posteriormente en una especie de modelo para los continuadores del movimiento de la Nueva Canción, por el contenido social de varias de sus letras, por el uso que hace Violeta Parra de una diversidad de ritmos folclóricos provenientes de diferentes zonas de Chile y por la presencia de instrumentos musicales vinculados a varios países sudamericanos. De hecho las canciones de este álbum parecen estar ordenadas con la expresa intención de enfatizar los contrastes entre ritmos binarios-ternarios, tempos lentosrápidos, danzas nortinas-sureñas, etcétera.

Algunas de las canciones de este último álbum revelan estados de ánimo diversos y complejos. Al menos cuatro de ellas demuestran una conexión directa con la figura de Gilbert Favré: Run run se fue pa'l norte (1966), Maldigo del alto cielo (1965), Una copla me ha cantado (1965) y la cueca Pastelero a tus pasteles (1966). Desde un punto de vista musical e iconográfico cabe señalar que el charango cumple un rol bastante simbólico en este álbum de Violeta Parra. De hecho la portada de este largaduración presenta una fotografía de la cantautora con este instrumento musical sobre su falda, el cual había sido obsequiado a Violeta Parra en La Paz, en 1966, por el propio Gilbert Favré ${ }^{10}$. El uso de un charango como

6 A fines de abril de 1966 Violeta Parra viajó a La Paz, Bolivia, con la finalidad de traer de regreso a Favré a Santiago de Chile. Él era en ese entonces un reconocido virtuoso en quena y decidió permanecer en La Paz como intérprete de dicho instrumento. En junio de ese mismo año Violeta viajó a Bolivia por segunda vez. En ese momento Favré se encontraba trabajando con el grupo musical Los Jairas en la Peña Naira, lugar en el cual Violeta Parra descubrió que estaba comprometido sentimentalmente con una joven boliviana. Ver Sáez 1999: 153-55.

7 En ese tiempo el público general ponía poca atención a la carpa de Violeta Parra en la comuna de La Reina en Santiago. Además ella comenzó a tomar fuertes medicamentos a fin de calmar su sistema nervioso. Ver Sáez 1999: 161.

8 Sáez 1999: 159.

9 Sáez 1999: 161.

10 Juan Pablo González agrega que las dos canciones interpretadas con este charango, Run run se fue pa'l norte (1966) y Gracias a la vida (1966), son dedicadas por Violeta Parra a Gilbert Favré. Ver González 2006: 176. 
único acompañamiento armónico en la canción Run run se fue pa'l norte (1966) buscaría precisamente enfatizar el contenido de esta canción mediante la evocación sonora del territorio boliviano donde su amado Gilbert residía por ese entonces ${ }^{11}$.

La canción que inicia este álbum es Gracias a la vida (1966), la cual Violeta Parra compusiera luego de su primer intento de suicidio en $1966^{12}$. Esta es también su canción más reconocida, la cual cuenta con cientos de versiones editadas en decenas de países, entre las que se destacan las interpretaciones de Mercedes Sosa, Plácido Domingo, Milva, Joan Báez, Omara Portuondo, Isabel Parra y la propia Violeta.

La folclorista Margot Loyola Palacios, amiga y comadre de Violeta Parra, se refirió en 1990 al carácter irónico que ella percibía en la canción Gracias a la vida, algo que no había sido notado previamente ni por los estudiosos ni por el público general $^{13}$. Nueve años más tarde el biógrafo de Violeta Parra, Fernando Sáez, concordó con esta percepción en la siguiente interpretación de la letra de esta canción: "compuesta luego del intento de suicidio de enero del ' $66,[\ldots]$ lejos de ser un himno a la vida, es un recuento poético de sus pérdidas" 14 . Nandorfy no descarta esta percepción "negativa" que hace Sáez de Gracias a la vida (1966), al reconocer su cercanía con las dimensiones autobiográficas del trabajo de Violeta Parra ${ }^{15}$.

Si Gracias a la vida tuviese un carácter irónico como lo señala Loyola y lo insinúa Sáez, la utilización de un charango como instrumento principal acompañante también debería ser parte del análisis ${ }^{16}$. En Run run se fue pa'l norte este instrumento refuerza la imagen de Gilbert Favré en Bolivia y, por ende, el estado de profunda decepción amorosa de la cantautora chilena. En tal sentido sería prudente asignar una interpretación similar a su presencia en Gracias a la vida. Además es importante recordar que la portada gráfica de este último álbum es justamente una fotografía de Violeta Parra interpretando charango, "con la mirada perdida en un horizonte inalcanzable" 17 .

Las seis estrofas de la canción siguen un patrón melódico y armónico distintivo. Cada una de ellas comienza con el mismo verso: "Gracias a la vida que me ha dado tanto", en los que la palabra "vida" siempre corresponde a un intervalo melódico de tritono (ver ejemplo 1).

11 En la grabación es posible distinguir dos charangos. El segundo de ellos presenta un timbre idéntico al primero y entra un compás más tarde. En Chile el charango está fuertemente asociado con la cultura boliviana más que con la peruana o argentina.

12 Sáez 1999: 159-60.

13 Referencia a comentarios vertidos por Margot Loyola en una de sus clases de Fundamentos de la Etnomúsica, una asignatura que impartiera en el Instituto de Música de la Pontificia Universidad Católica de Valparaíso.

14 Sáez 1999: 159-160.

15 Nandorfy 2003: 199.

16 Violeta Parra utilizó el charango solo en dos composiciones de su último álbum: Run Run se fue pa'l norte (1966) y Gracias a la vida (1966). En otra canción de este mismo álbum, Mazúrquica modérnica (1965), la voz de Violeta Parra es acompañada por un charanguito, según información proporcionada en la contraportada del LP Las últimas composiciones de Violeta Parra, RCA Víctor, CML-2456, 1966.

17 González 2006:176. 
Ejemplo 1. Gracias a la vida, primera frase.

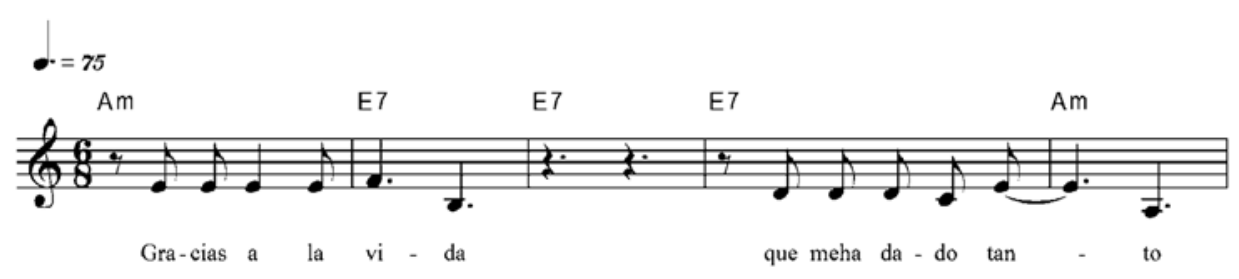

Aunque el intervalo de tritono forma parte del acorde de dominante séptima, función armónica de amplia presencia en el repertorio folclórico chileno, es interesante observar que Violeta Parra haya hecho expreso uso de este intervalo en contextos de términos como "dominación", "dolor" e "injusticia social”. En el año 2007 Lucy Oporto analizó ampliamente el uso que Violeta Parra hace del intervalo de tritono en El gavilán, pieza para voz y guitarra compuesta hacia fines de la década de 1950 y concebida como música para ballet. Según palabras de Oporto:

"El gavilán relata la historia de una mujer engañada, traicionada y asesinada por un ser masculino, Gavilán, que aquí aparece como transfiguración del Diablo y expresión del odio de la comunidad hacia la víctima. El tritono constituye el núcleo de la estructura formal de El gavilán, en correspondencia con su referente extraformal: la tensión entre la prepotencia y hegemonía del asesino sobre la víctima, y el inenarrable sufrimiento de ésta"18.

Mediante la grabación realizada por Violeta Parra en París en 1964, Oporto realiza un análisis formal de El gavilán basado en la presencia de intervalos de tritono a lo largo de esta pieza. Para ello distingue dos grandes secciones que ella denomina como: (1) destrucción del orden de la víctima y (2) reconstitución del orden de la comunidad, a partir de su sacrificio y asesinato. Sobre la base de la transcripción en partitura que el guitarrista Mauricio Valdebenito hiciera en 2001 a partir de una versión registrada por el compositor chileno Miguel Letelier hacia fines de la década de 1950, Oporto entrega un detallado informe acerca de los compases en los cuales es posible distinguir tritonos. La obra la divide en cuatro secciones denominadas como (1) Cueca feroz, (2) Dolor de la víctima, (3) Comunidad homicida y (4) Rasgueo homicida ${ }^{19}$.

En sus canciones Qué pena siente el alma, La lavandera y Los pueblos americanos (ver ejemplo 2) es posible apreciar otros usos que Violeta Parra hace del intervalo de tritono. En su elegía Canto para una semilla, el compositor chileno Luis Advis (1935-2004) pone de relieve la asociación establecida por la cantautora chilena entre este intervalo y el concepto de "injusticia social" en Los pueblos americanos. Canto para una semilla está basado en la autobiografía en décimas de Violeta Parra. Relata la vida de la cantautora chilena y sigue un curso dramático cuyo clímax ocurre en el séptimo movimiento con la muerte de Violeta.

18 Oporto 2007:28.

19 Oporto 2007:96-105. 
En el sexto movimiento se aprecia la acentuada presencia de un intervalo de tritono (Fa\#-Do), el que es probablemente utilizado por Advis para expresar la indignación que él percibe en la cantautora chilena respecto de la desigualdad social en Chile, y su íntimo deseo de revertir este orden. Este tritono es ejecutado en tres oportunidades por el tenor solista con un acompañamiento rítmico basado en rasgueos sobre cuerdas tapadas y güiro. La última aparición de este tritono (Fa\#-Do) ocurre sobre la frase "Cuando se dé la tortilla la vuelta que tanto anhelo" y es ejecutado al unísono por todas las voces masculinas, sin acompañamiento alguno, resolviendo por semitono descendente al sonido Si. En el manuscrito, este tritono está señalado con dinámica fortissimo seguida por la indicación “¿Pausa?”, la que alude claramente al momento del suicidio. Luego del séptimo movimiento llamado "la muerte" Advis incluyó el texto de Gracias a la vida en la narración.

Ejemplo 2. Los pueblos americanos, primera frase.

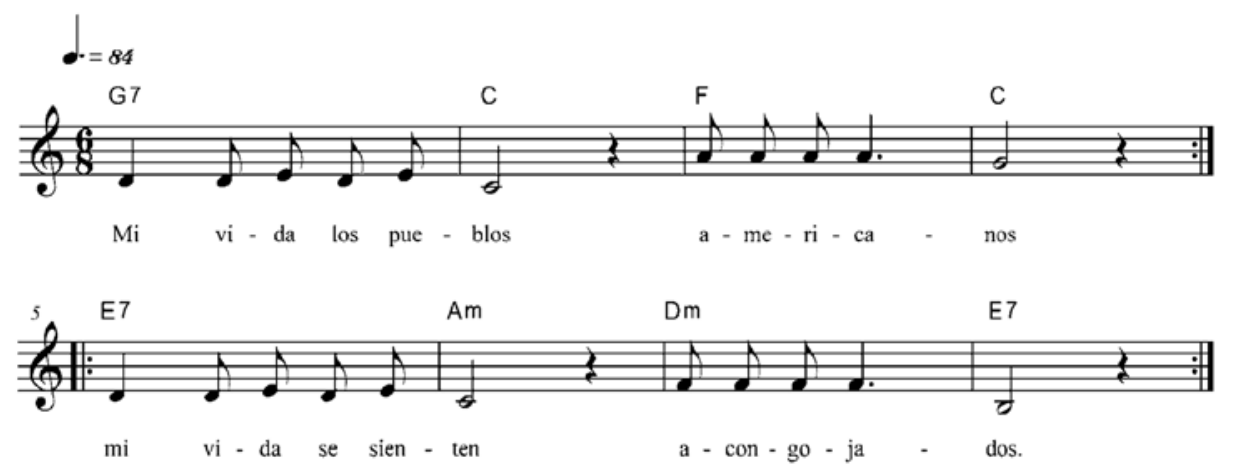

En suma, el tritono melódico presente en el motivo inicial de Gracias a la vida (1966) podría ser interpretado como una expresión del descontento e inestabilidad emocional sufridos por Violeta Parra en 1966-67. Esto, unido a la utilización de charango como principal instrumento armónico acompañante, revelaría el posible carácter irónico de su letra de un modo estrictamente musical.

\section{EL “ACORDE MÍSTICO” DE GARRIDO-LECGA}

El período de síntesis en la obra de Garrido-Lecca señalado a partir de 1985 no solo se caracteriza por una mezcla de elementos musicales provenientes de diversas tradiciones (clásica, folclórica y popular), sino que también por una nueva manera de organizar las alturas sobre la base de un acorde original creado por el compositor ese mismo año. Garrido-Lecca se declara un admirador de la música de Alexander Scriabin. El establecimiento de un acorde personal como soporte formal de sus obras post-1985 está claramente inspirado en el "acorde místico" de este compositor ruso. Este acorde lo estrenó Scriabin en su obra orquestal 
Prometheus compuesta entre 1908 y 1910. Está también presente en las últimas cinco de sus diez sonatas para piano y en un número de composiciones breves para piano escritas entre 1908 y 1913.

Scriabin aparentemente concibió su acorde como una serie de diversos intervalos de cuarta ascendentes (Do-Fa\#-Sib-Mi-La-Re). No obstante también se asemeja a una escala hexáfona cuyo quinto grado (Lab) ha sido reemplazado por La natural (Do-Re-Mi-Fa\#-La-Sib). Con la sola carencia del sonido Sol, el "acorde místico" de Scriabin también podría organizarse como una sucesión de terceras ascendentes. Morgan señala que en las obras tardías de este compositor ruso, los materiales armónicos y melódicos derivan de este acorde, el cual actúa como una especie de tónica en sí misma ${ }^{20}$. Junto con el "acorde místico", otros cinco símbolos musicales han sido identificados en las últimas sonatas para piano de Scriabin, los que muestran la asociación de características musicales específicas con ciertas imágenes o ideas ${ }^{21}$.

Aunque Garrido-Lecca no ha querido asignar un nombre particular a su acorde personal, uno puede notar por medio de conversaciones que él lo señala como su "acorde místico" propio ${ }^{22}$. Este contiene cuatro alturas que condensan los doce intervalos que se producen dentro de un ámbito de octava, representados en forma descendente por los sonidos Do-Si-La-Fa ${ }^{23}$. En el ejemplo 3 es posible observar el acorde completo (a) y un detalle de los seis intervalos más pequeños que se producen por la combinación de estas cuatro alturas: segunda menor (b), segunda mayor (c), tercera menor (d), tercera mayor (e), cuarta justa (f) y cuarta aumentada (g). El resto de los intervalos se producen por la inversión de los intervalos señalados anteriormente, mientras el unísono y la octava justa pueden ser generados a partir de cualquier altura de este acorde.

20 Morgan 1990: 56-57.

21 El motivo de "fanfarria", frecuentemente presentado como un gesto anacrúsico formado por una, dos o tres notas breves, sugiere el llamado de un ente sobrenatural, poderoso o de algún origen misterioso. El motivo "eternamente femenino" representa al erotismo por medio de su lirismo, cromatismo y su estilo rítmico improvisatorio. El "motivo de luz" alude a la iluminación divina, y es frecuentemente expresado en las últimas obras de Scriabin en forma de trinos, trémolos u otras ornamentaciones. El "motivo de vuelo" usualmente toma la forma de arpegios rápidos de cinco notas y refleja su visión del vuelo como un enlace entre dos planos de existencia, el material y el espiritual. Un último motivo denominado "danzas vertiginosas" representa el logro del éxtasis mediante danzas giratorias intoxicantes. Estos pasajes son identificados en las obras de Scriabin por términos franceses como vertige, délire y tourbillonnant. Ver García 2000: 278-86.

22 Referencia a nueve extensas conversaciones telefónicas sostenidas con el compositor y dos entrevistas personales realizadas entre el 4 de marzo de 2009 y el 31 de marzo de 2010. Las transcripciones de estas conversaciones se encuentran disponibles en Niño 2011: 348-436.

23 Cualquier alusión posterior a esta serie aparecerá en la forma de un tetracordio descendente, siguiendo un concepto propuesto por Raoúl y Marguerite d'Harcourt en 1925. Con ello se ilustra el movimiento usualmente descendente que presentan las melodías andinas, característica que es prominente también en la música de Garrido-Lecca. 
Ejemplo 3. El "acorde místico" de Garrido-Lecca y los seis intervalos más pequeños producidos por la combinación de estas cuatro alturas.

a)

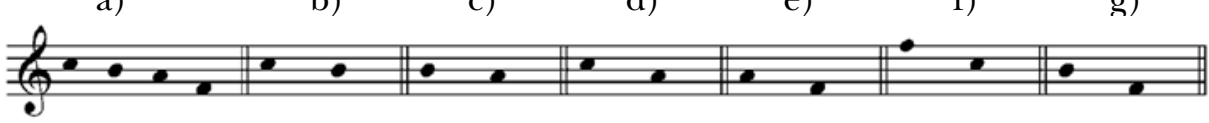

En muchas de sus obras posteriores a 1985 Garrido-Lecca presenta este grupo de cuatro sonidos en forma de acorde o de arpegios, cuya sonoridad vertical es equivalente a una tríada mayor con una cuarta aumentada agregada ${ }^{24}$. Al organizar este grupo de sonidos en pares de díadas, se generan tres posibles combinaciones que se ilustran en el ejemplo 4.

Ejemplo 4. El "acorde místico" de Garrido-Lecca organizado en pares de díadas: $a$, segunda menor y tercera mayor; $b$, tercera menor y cuarta aumentada; $c$, quinta justa y segunda mayor.

a)

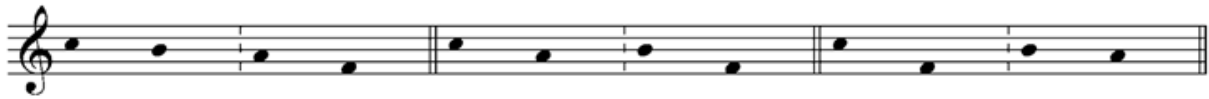

Dentro de estas posibilidades, Garrido-Lecca demuestra en sus obras posteriores a 1985 una particular preferencia por la segunda opción (b), constituida por la combinación de una tercera menor y una cuarta aumentada. El intervalo de tercera menor está estrechamente vinculado con la música andina, en particular con una de las escalas pentatónicas anhemitónicas más comunes del repertorio campesino peruano, de acuerdo con los estudiosos franceses Raoúl y Marguerite d'Harcourt ${ }^{25}$. Las razones por la preferencia de Garrido-Lecca hacia el intervalo de tritono, sin embargo, son más difíciles de dilucidar, principalmente porque el propio compositor no ha entregado una explicación definitiva al respecto.

\section{TRÍO PARA UN NUEVO TIEMPO}

El primer movimiento de Trío para un nuevo tiempo (1985) muestra una serie de elementos musicales que caracterizan el estilo de Garrido-Lecca a partir de 1985. A lo largo de este movimiento se puede observar un énfasis en los intervalos de tercera menor y de tritono, la presencia de elementos melódicos y rítmicos de la tradición andina, el estreno de su "acorde místico", el tratamiento polifónico de

24 El "acorde místico" de Garrido-Lecca se hace evidente en Eventos de 1993, una obra para orquesta de cámara que se inicia justamente con este acorde.

25 D'Harcourt y D'Harcourt 1990: 132. 
los instrumentos de cuerda, el establecimiento de ostinatos y pedales, la utilización de sonidos armónicos y de acciaccaturas, entre otros.

En los primeros tres compases de la obra, Garrido-Lecca presenta un primer motivo en el piano que comprende las doce alturas del sistema musical occidental y donde los intervalos de terceras mayores y menores son prominentes. El violín y el violonchelo enfatizan la tercera menor en las alturas Sol y Sib, incluyendo la ejecución directa de las cuerdas por parte del pianista (ver ejemplo 5$)^{26}$.

Ejemplo 5. Trío para un nuevo tiempo, primer movimiento, cc.1-6.

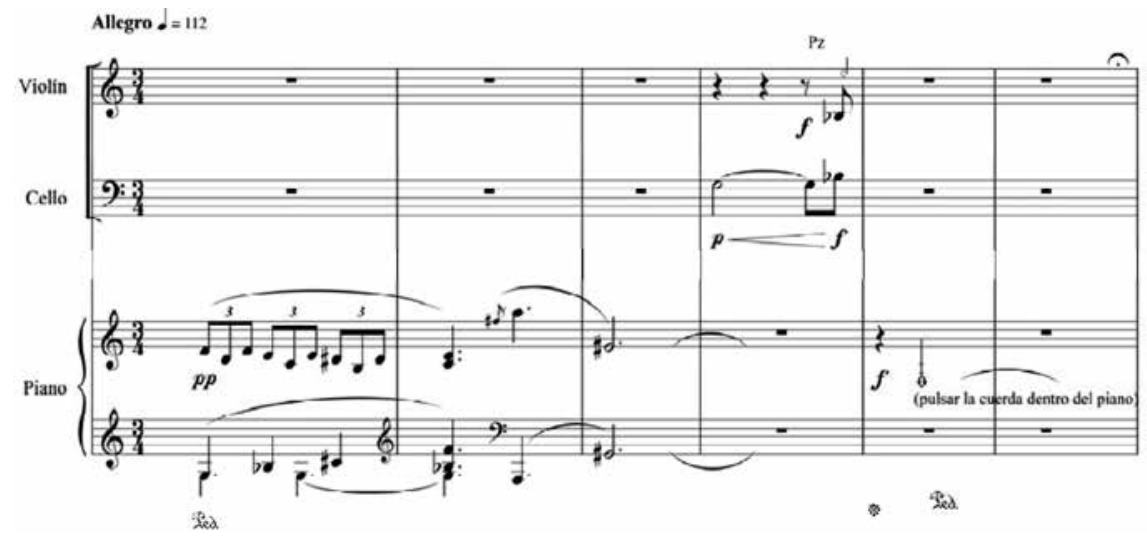

Este mismo intervalo será posteriormente enfatizado mediante su presentación simultánea en los tres instrumentos, en cuatro diferentes octavas y en dinámica fortissimo, en el compás 21 (ver ejemplo 6).

Ejemplo 6. Trío para un nuevo tiempo, primer movimiento, cc.18-22.

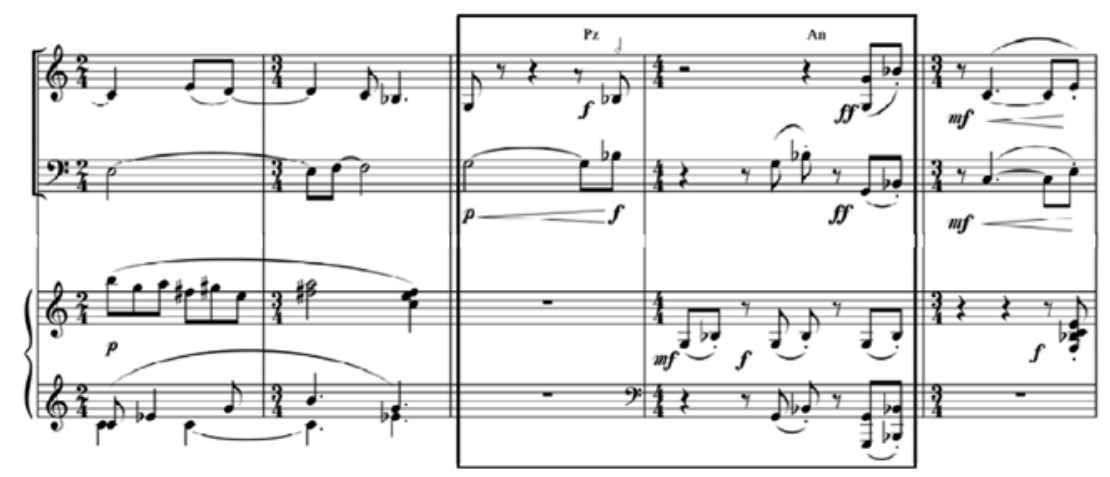

26 Esta primera frase es repetida con ligeras variaciones entre los compases 7 y 16 . La altura Sol, por ejemplo, es tocada tres veces más por el pianista utilizando el teclado, pero la cuerda debe ser tapada por la mano derecha del pianista. 
En el primer pulso del compás 37 el "acorde místico" de Garrido-Lecca es reconocible por vez primera en la mano derecha del piano, formado por las alturas Lab-Sol-Fa-Reb. Este acorde se repite en el segundo pulso del siguiente compás (ver ejemplo 7).

Ejemplo 7. Trío para un nuevo tiempo, primer movimiento, cc.36-39.

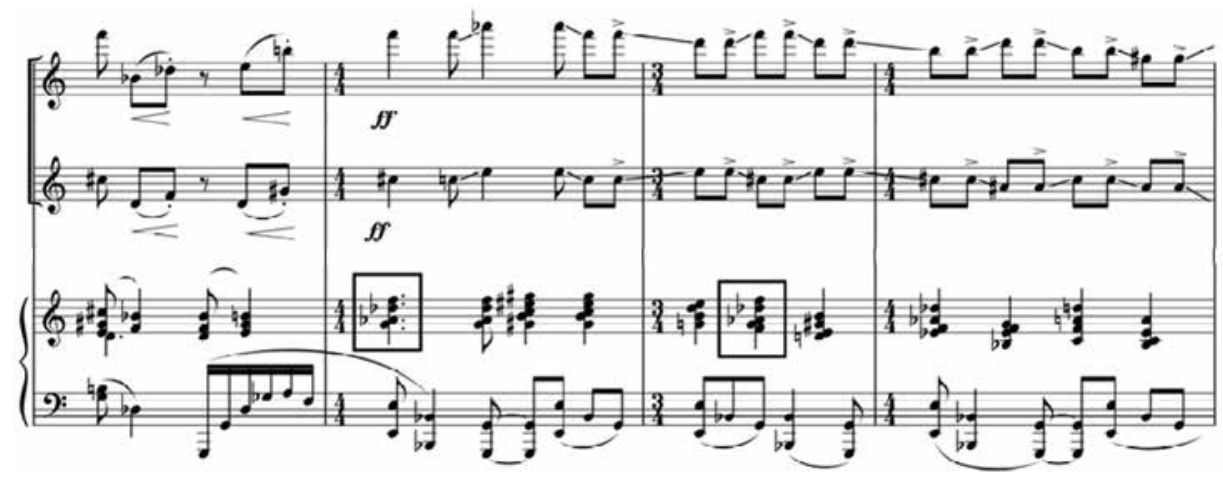

Entre los compases 56 y 58 se advierte una clara alusión a la tradición musical andina campesina con la presentación en la mano derecha del piano de un gesto melódico agudo y descendente de ritmos sincopados, acompañado por terceras paralelas mayores y menores ${ }^{27}$. Posteriormente el violonchelo inicia un ostinato conformado por tres notas (Re\#-Fa\#-Do), una idea que se prolonga por diecisiete compases (ver ejemplo 8).

Ejemplo 8. Trío para un nuevo tiempo, primer movimiento, cc.56-59.

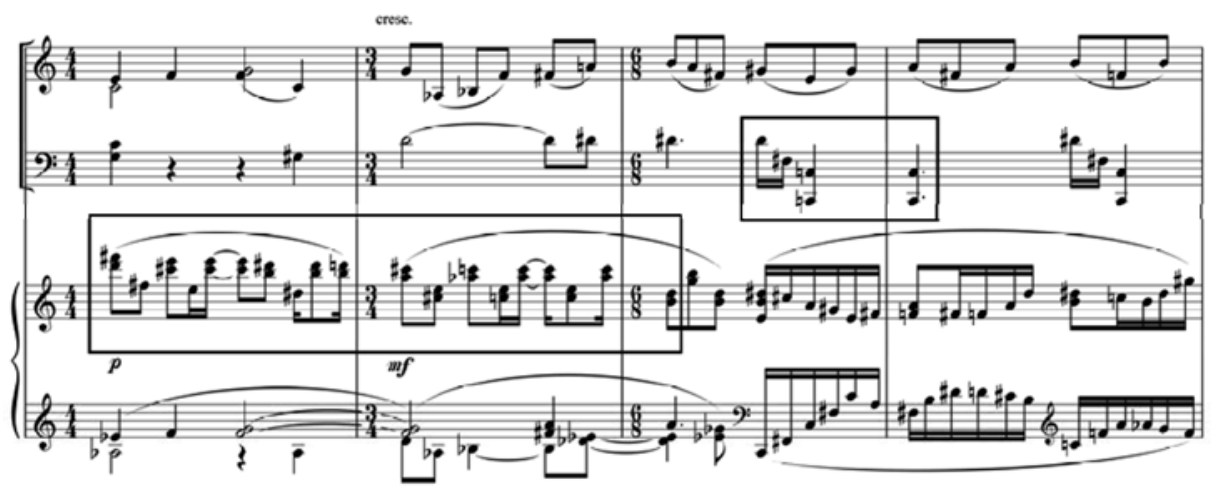

27 La alternancia de terceras paralelas, menores y mayores, se observa en muchas obras de Garrido-Lecca, así como también en obras de otros compositores peruanos contemporáneos. Este signo ha recibido el nombre de "terceras arequipeñas" y ha sido vinculado al nacionalismo peruano. Ver Béhague 1979: 311. 
Hacia el final del primer movimiento el intervalo de tritono adquiere un papel predominante, como se puede apreciar en las líneas melódicas de los tres instrumentos entre los compases 76 y 79. Esto anticipa el rol trascendental que este intervalo asume en el segundo movimiento de la obra (ver ejemplo 9).

Ejemplo 9. Trío para un nuevo tiempo, primer movimiento, cc.76-79.

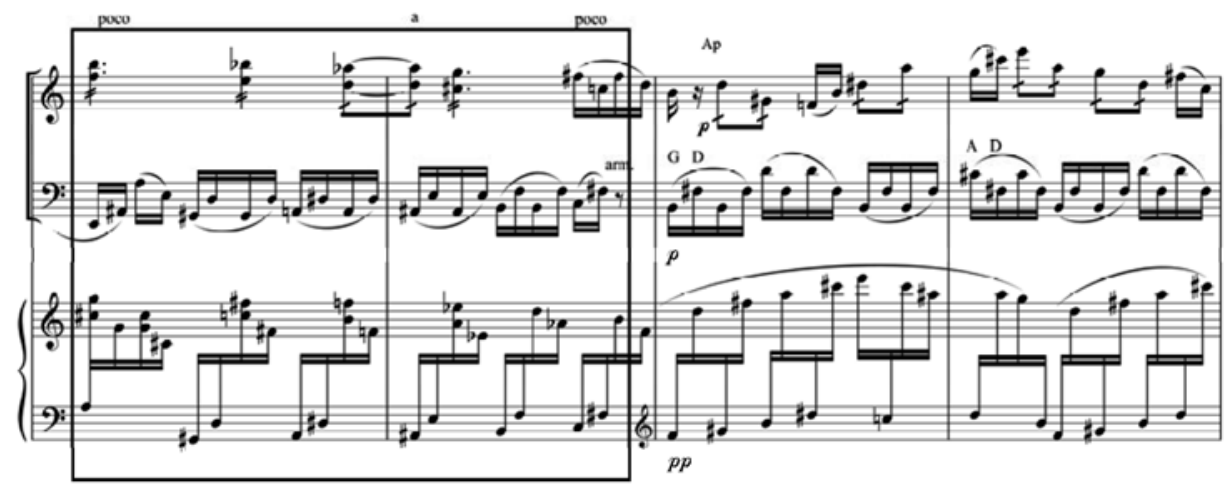

Según ya se ha señalado, el segundo movimiento de Trío para un nuevo tiempo (1985) está basado en la canción Gracias a la vida, compuesta por Violeta Parra en 1966. La primera frase de esta canción contiene dos motivos principales separados por un compás de silencio (ver ejemplo 10).

Ejemplo 10. Gracias a la vida, primera frase.

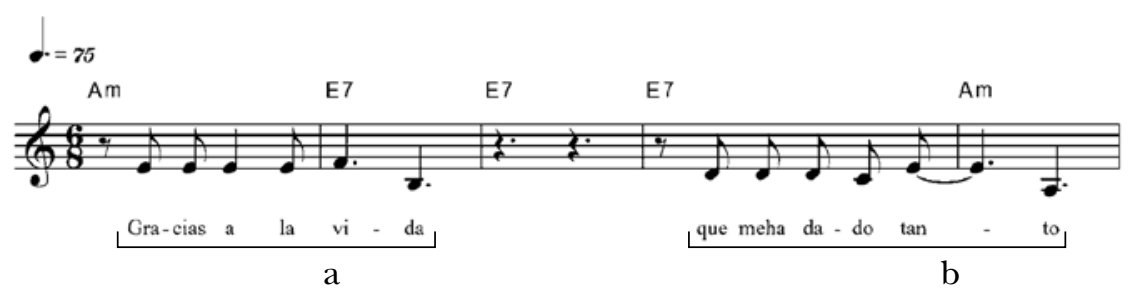

El primer motivo expresa tensión por medio de su característico tritono final que se acompaña con un acorde de dominante séptima (a), mientras que el segundo motivo, constituido por cuatro alturas diferentes, denota reposo a través de un intervalo conclusivo de quinta justa y su retorno a la tónica (b). Ambos motivos son especialmente desarrollados por Garrido-Lecca a lo largo del segundo movimiento.

En aparente concordancia con la fecha de composición de Gracias a la vida (1966), el segundo movimiento del trío contiene una indicación metronómica de sesenta y seis pulsos por minuto. Debido a que esta canción fue originalmente acompañada por la propia Violeta Parra con el distintivo timbre de un charango, 
Garrido-Lecca decidió imitar la sonoridad de este instrumento andino al comienzo del movimiento para lo que prescribe al pianista rasguear las cuerdas directamente con su mano derecha sobre el encordado del instrumento ${ }^{28}$. Al inicio del movimiento los tres instrumentos se encuentran en registro soprano, con la clara intención de imitar el sonido rasposo de la voz de Violeta Parra por medio del registro agudo del violonchelo (ver ejemplo 11).

Ejemplo 11. Trío para un nuevo tiempo, segundo movimiento, cc.1-6.

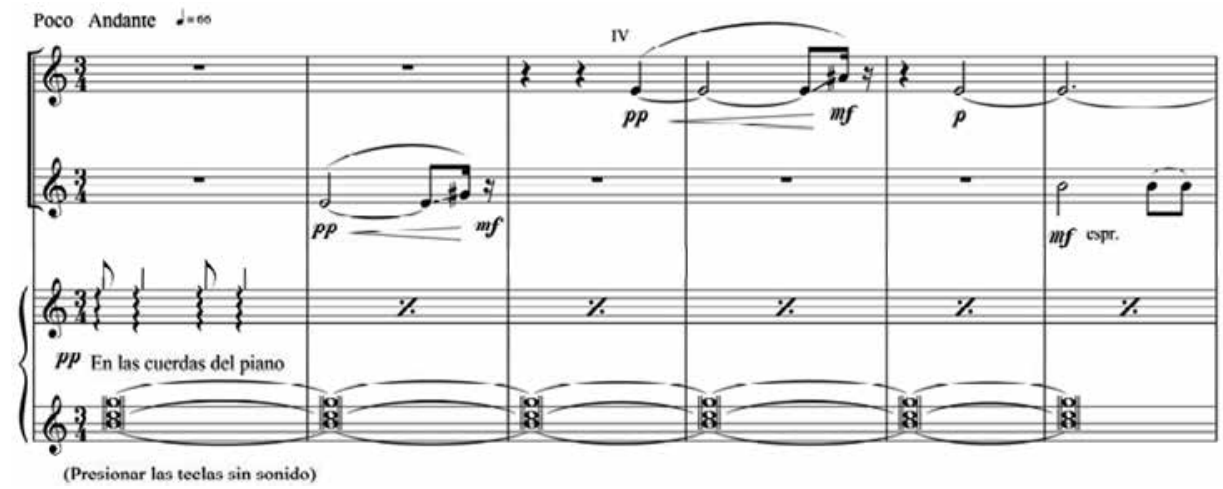

Aunque el diseño melódico de Violeta Parra es reconocible, la canción se encuentra totalmente transformada por Garrido-Lecca no solo en términos de tonalidad, metro y tempo, sino que también por la agregación de nuevas alturas a su melodía. En el ejemplo 12 se observa que la melodía original es identificable hasta el compás 15 donde un primer tritono (Re-Lab) interrumpe la referencia; en el siguiente compás un segundo tritono (Fa-Si) concluye la cita. Según sus propias palabras, Garrido-Lecca utiliza el tritono en este caso para "escapar" de la cita. En obras posteriores el compositor utilizará este mismo recurso para "huir" de otras melodías tonales, modales o pentatónicas.

Ejemplo 12. Trío para un nuevo tiempo, segundo movimiento, cc.6-18 (violonchelo).

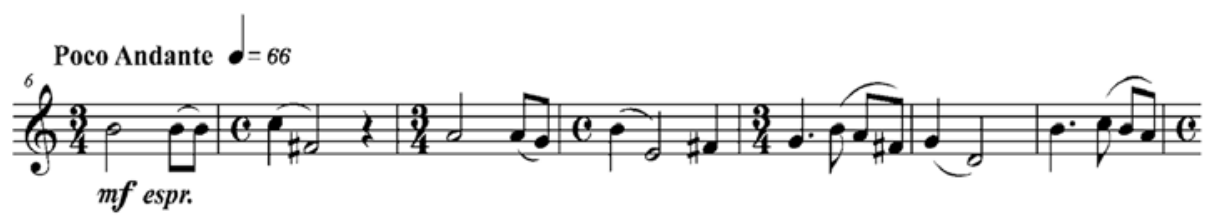

28 Aunque este efecto está claramente expresado en la partitura, es prácticamente imposible producirlo en muchos pianos debido a la presencia de barras de acero sobre el encordado. Consecuente con ello, la partitura ofrece una segunda opción que es tocar los acordes en forma de arpegios, siguiendo los ritmos escritos originalmente para la mano derecha. 


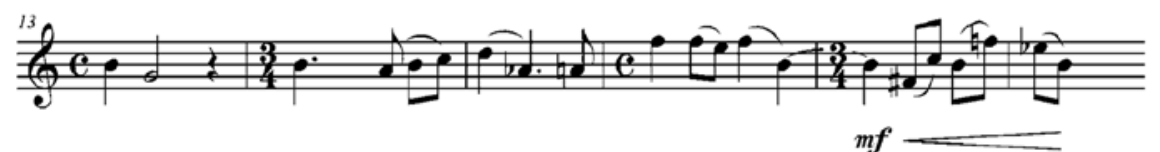

A continuación, el primer motivo de Gracias a la vida (a) aparece en la voz superior del violín en los compases 18-19, enfatizado con acentos y dinámicas forte. Una vez que la cita de la canción de Violeta Parra se hace evidente, el intervalo de tritono comienza a adquirir un rol fundamental, especialmente en las melodías y acordes que ejecuta la mano izquierda del piano (ver ejemplo 13).

Ejemplo 13. Trío para un nuevo tiempo, segundo movimiento, cc.17-20.

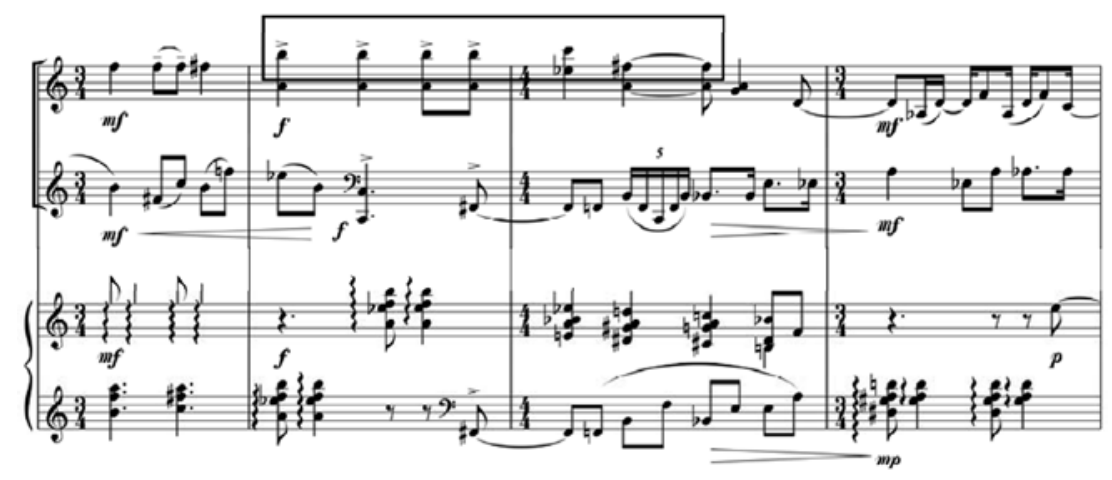

Entre los compases 28 y 32 la sonoridad general del ensamble es muy aguda, pero en el contexto de un piano subito. El violonchelo contribuye a este nuevo ambiente mediante el uso de armónicos y citando dos veces el segundo motivo de Gracias a la vida (b). En el compás 30 el violín presenta un prominente tritono entre ambas citas (Do-Fa\#) como una especie de recordatorio del primer motivo de la popular canción (ver ejemplo 14).

Ejemplo 14. Trío para un nuevo tiempo, segundo movimiento, cc.28-32.

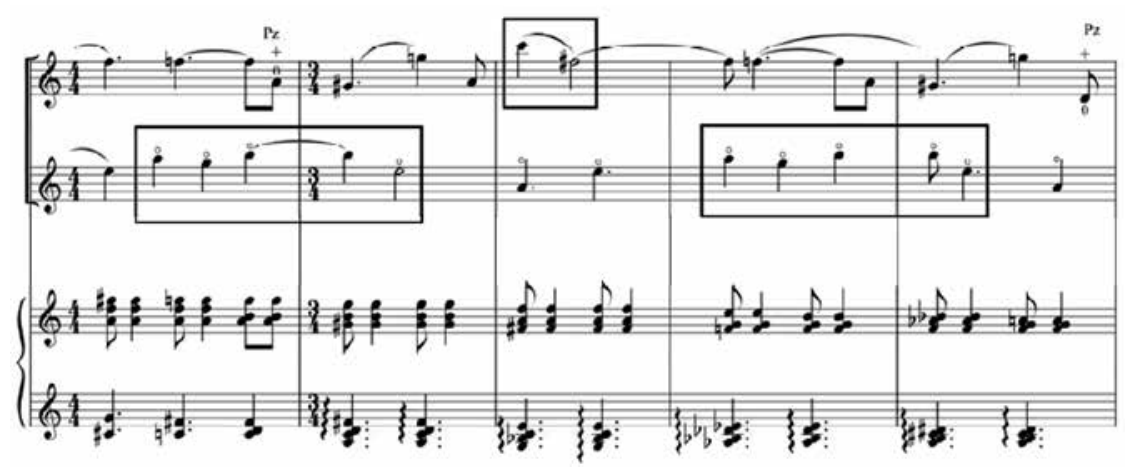


Hacia la mitad del segundo movimiento el auditor se encuentra con un inesperado cambio de atmósfera ${ }^{29}$. El tempo, las dinámicas y la articulación cambian y todos los instrumentos derivan hacia sus registros más graves ${ }^{30}$. Si bien en un principio esta nueva sección pareciera estar desconectada de la canción de Violeta Parra, puede observarse que la cabeza del motivo del violonchelo corresponde exactamente a las cuatro notas del segundo motivo de Gracias a la vida (b), las cuales habían sido ejecutadas previamente por este mismo instrumento en armónicos. Simultáneamente la mano izquierda del piano inicia un ostinato consistente en un reconocible tritono (Fa\#-Do) en articulación staccato, una idea que continúa hasta el tiempo fuerte del compás 53 (ver ejemplo 15).

Ejemplo 15. Trío para un nuevo tiempo, segundo movimiento, cc.39-43.

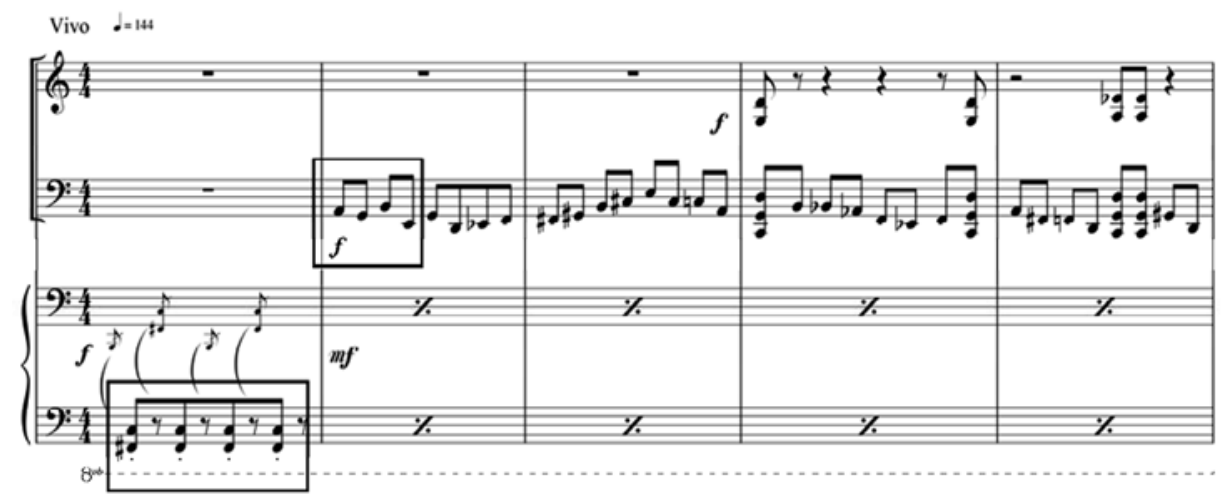

En el compás 53 una serie de glissandi del violonchelo en quintas ascendentes introducen una nueva exposición del tema por el violín en pizzicato basada en el segundo motivo de Gracias a la vida (1966). La melodía comienza con las cuatro notas del motivo original ejecutadas en el registro más bajo del instrumento (ver ejemplo 16) ${ }^{31}$.

29 Situaciones equivalentes se observan en otras obras de Celso Garrido-Lecca. Su obra Intihuatana (1967) para cuarteto de cuerdas posee una estructura palindrómica. Esto implica que al centro de la obra se ubica un espejo imaginario a partir del cual se refleja toda la segunda parte. En su Cuarteto de cuerdas $\mathrm{N}^{\circ} 2$ de 1987, escrito a la memoria de Víctor Jara, existe un pasaje percusivo en la mitad exacta de la obra que no se observa en ningún otro momento de la misma.

30 Aunque la partitura no señala un cambio de articulación en este punto, la versión grabada por el Trío Arte en 1987 bajo la supervisión del mismo compositor contiene el uso de pizzicati en las cuerdas.

31 Este motivo es presentado nuevamente por el violonchelo en el compás 65 y finalmente por el violín en el compás 67 sobre un tritono que es ejecutado por el piano a manera de ostinato. 
Ejemplo 16. Trío para un nuevo tiempo, segundo movimiento, cc.53-56.

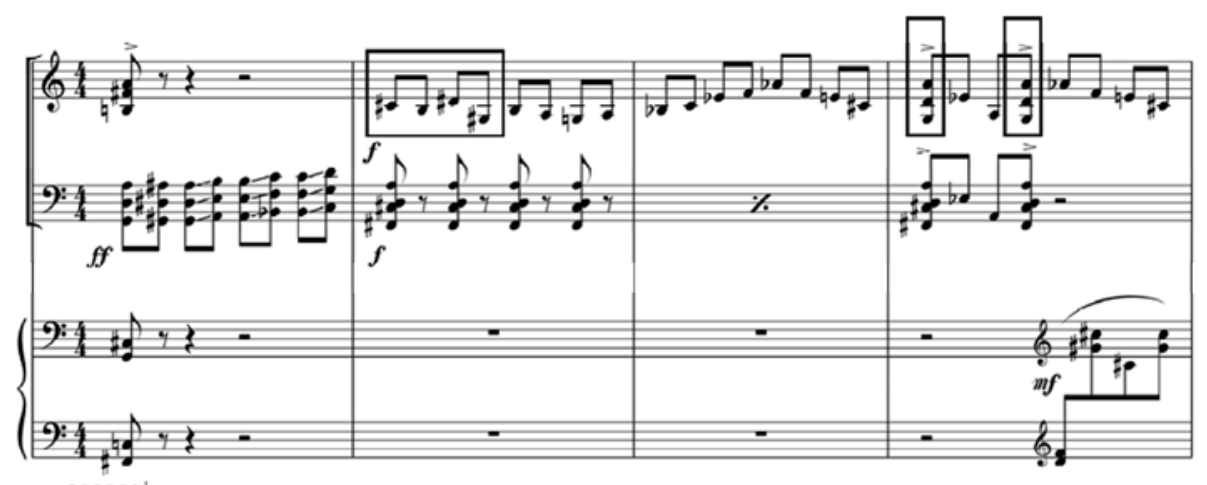

Al término del movimiento el "acorde místico" de Garrido-Lecca aparece en dos diferentes versiones, como si se tratase de una tétrada que cumple funciones de tónica. Esto se verifica en la mano izquierda del piano en el compás 80 , entre los compases 82-83 (Sib-La-Sol-Mib) y al finalizar la cadenza del piano (Mi-Re\#Do\#-La) (ver ejemplos 17 y 18).

Ejemplo 17. Trío para un nuevo tiempo, segundo movimiento, cc.79-83.

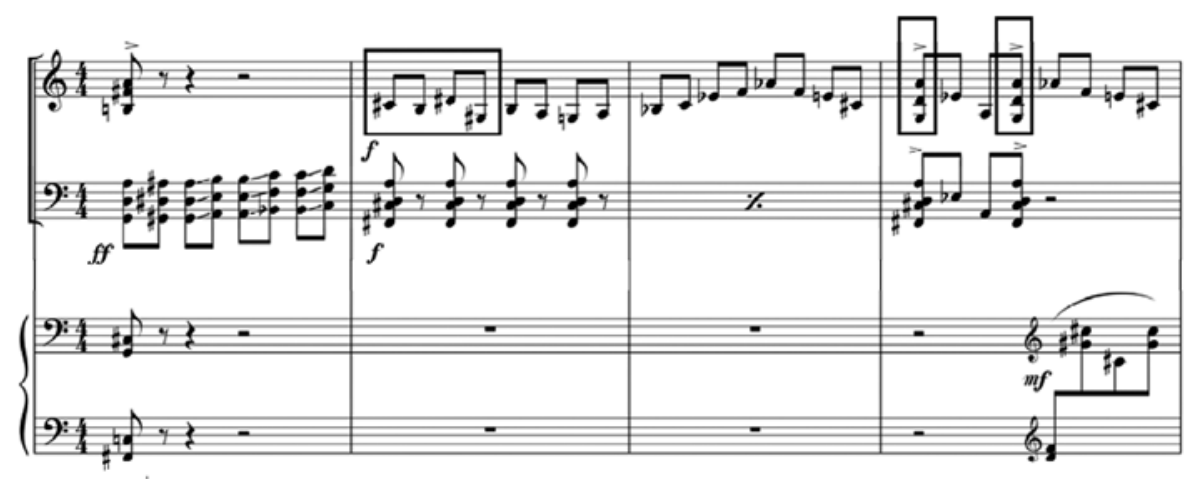

Ejemplo 18. Trío para un nuevo tiempo, segundo movimiento, c.84 (fin de la cadenza del piano).

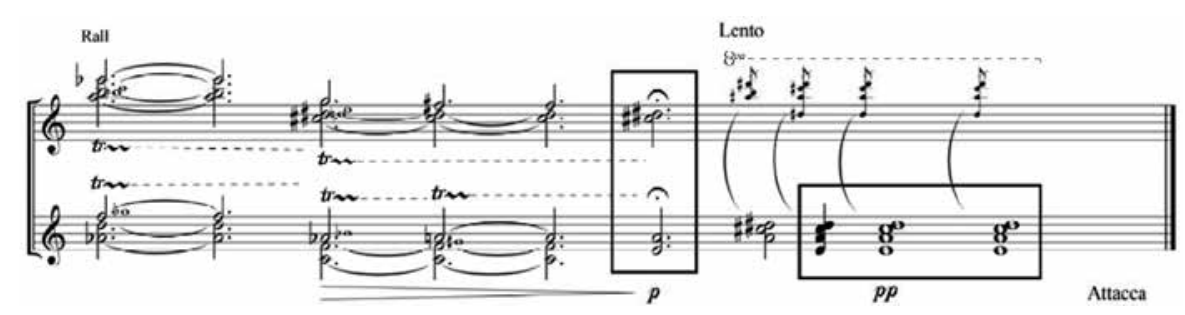


El tercer movimiento de Trío para un nuevo tiempo se encuentra escrito en metro de 5/8, el que no guarda relación ni con la tradición folclórica chilena ni con la peruana, aunque sí guarda semejanza con ciertas piezas musicales vinculadas al movimiento de la Nueva Canción ${ }^{32}$. De acuerdo con el mismo Garrido-Lecca, él aplica estos metros en sus composiciones con la expresa intención de romper la regularidad métrica binaria y ternaria, tan propia de la música folclórica sudamericana. Por este solo hecho el tercer movimiento contrasta con los dos anteriores. A esto se suma la presencia de una melodía inicial en modo Mixolidio y la frecuente cita de melodías andinas a lo largo de él. Con una nueva indicación de tempo, el violín presenta por primera vez una melodía pentatónica anhemitónica distintiva entre los compases 41 y 45 en su voz superior (ver ejemplo 19).

Ejemplo 19. Trío para un nuevo tiempo, tercer movimiento, cc.41-45 (violín).

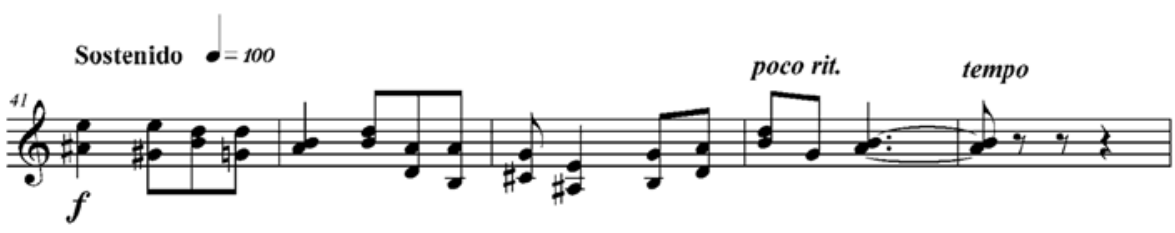

Una segunda versión de la misma melodía pentatónica es presentada a continuación por el violín entre los compases 51 y 55, la que aparece duplicada por la mano derecha del piano y reforzada por medio de acordes (ver ejemplo 20).

Ejemplo 20. Trío para un nuevo tiempo, tercer movimiento, cc.50-55.

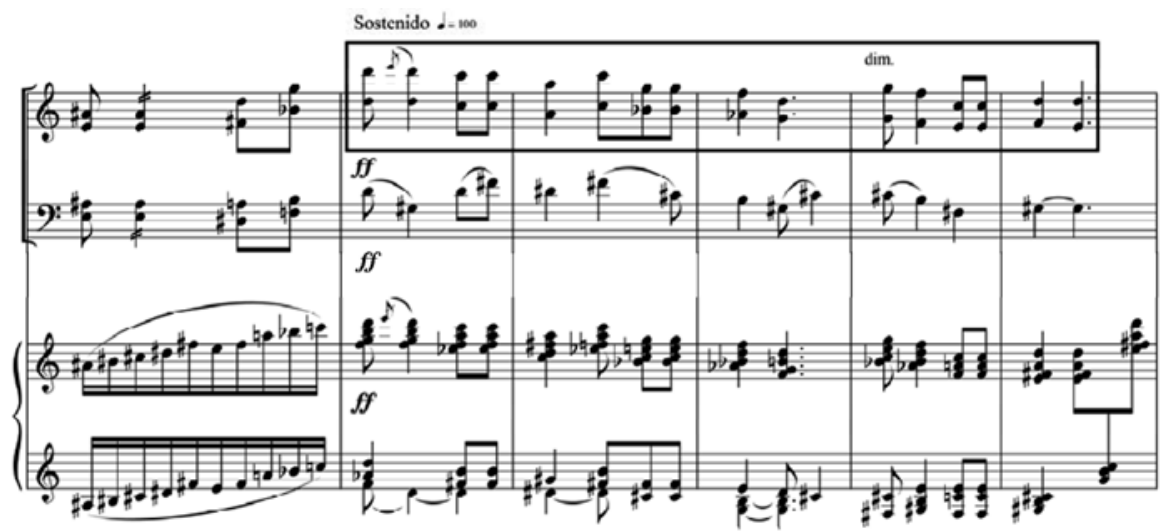

32 Se puede señalar, a modo de ejemplo, que en 1971 el compositor chileno Luis Advis usó un metro similar en el movimiento final de su elegía Canto para una semilla, obra basada en la autobiografía en décimas de Violeta Parra. Algunos años más tarde el propio Celso Garrido-Lecca compuso un tema instrumental llamado Tiempo nuevo que combina metros de $6 / 8$ y $7 / 8$, en una pieza que formaba parte del repertorio original del grupo musical que llevaba dicho nombre. 
En adición a su estructura pentatónica el gesto melódico descendente inicial refuerza su carácter andino. Aunque Garrido-Lecca no pudo identificar con exactitud el origen de la melodía aquí citada, él menciona que ella ciertamente forma parte del repertorio adquirido durante sus años dedicados al estudio de la música andina peruana ${ }^{33}$.

A mediados del tercer movimiento, específicamente en el compás 92, se inicia una nueva sección precedida por doble barra. A partir de este punto Garrido-Lecca cambia el metro de $5 / 8$ por dos metros que alternan $3 / 4$ y $2 / 4$ (ver ejemplo 21 ).

Ejemplo 21. Trío para un nuevo tiempo, tercer movimiento, cc.89-94.

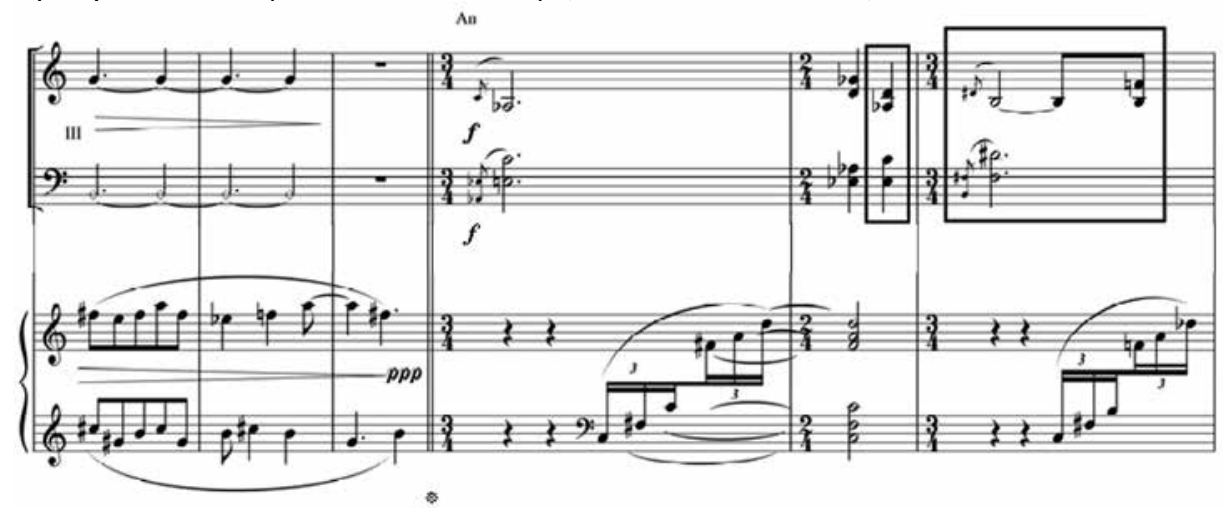

A lo largo de este segmento su "acorde místico" es prominente y se pueden identificar a lo menos quince versiones de esta serie entre los compases 93 y 126. Esta sección finaliza con una cadenza interpretada por violín y violonchelo.

Dentro de esta misma sección el violín presenta una nueva melodía andina entre los compases 100 y 107, que se caracteriza por contener una serie de ornamentaciones melódicas rápidas en forma de acciaccaturas (ver ejemplo 22).

Ejemplo 22. Trío para un nuevo tiempo, tercer movimiento, cc.100-107 (violín).

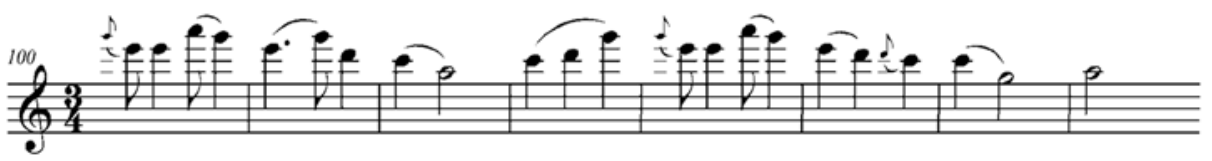

Mientras esta melodía es ejecutada por el violín en su registro agudo, los otros instrumentos acompañan con melodías y arpegios también agudos, produciendo

33 Hacia fines de la década de 1940 Garrido-Lecca conoció en Lima a Dino Huata, un ejecutante de sicus proveniente de la isla de Taquile, ubicada en medio del lago Titicaca. Este músico le interpretó una serie de melodías tradicionales de su lugar de origen, las cuales Garrido-Lecca transcribió en partitura con fines de estudio. Según el propio compositor, este tipo de melodías afloran naturalmente durante su proceso compositivo. 
una sonoridad muy particular que evoca aquella preferencia de los habitantes andinos por las frecuencias altas (ver ejemplo 23).

Ejemplo 23. Trío para un nuevo tiempo, tercer movimiento, cc.99-102.

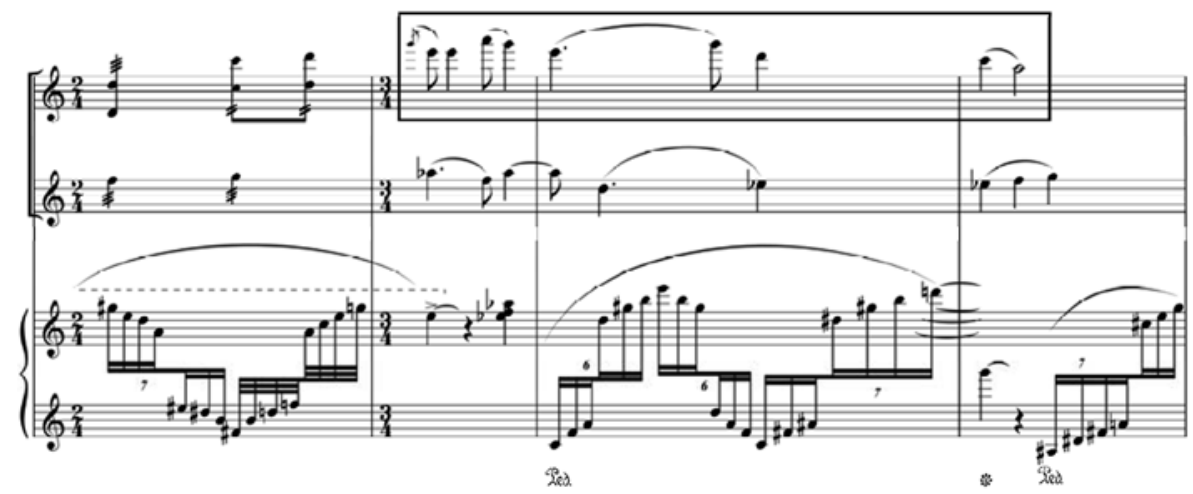

El "acorde místico" de Garrido-Lecca es aun más prominente antes de la última cadenza. Entre los compases 123 y 126 se observan tres versiones de este acorde en una secuencia ascendente de terceras menores, las que son siempre ejecutadas por las cuerdas y enfatizadas por trémolos o articulación staccato ${ }^{34}$. La primera de estas versiones, Mib-Re-Do-Lab, ocurre en el segundo pulso del compás 123; Fa\#Fa-Re\#-Si es verificable en el primer pulso del compás 124 y en el segundo pulso del compás 125; finalmente, La-Sol\#-Fa\#-Re, ocurre en el primer pulso del compás $126^{35}$. Alrededor de estos acordes, el violín y el violonchelo presentan diversas díadas conformadas por quintas justas y tritonos (ver ejemplo 24).

Ejemplo 24. Trío para un nuevo tiempo, tercer movimiento, cc.123-126.

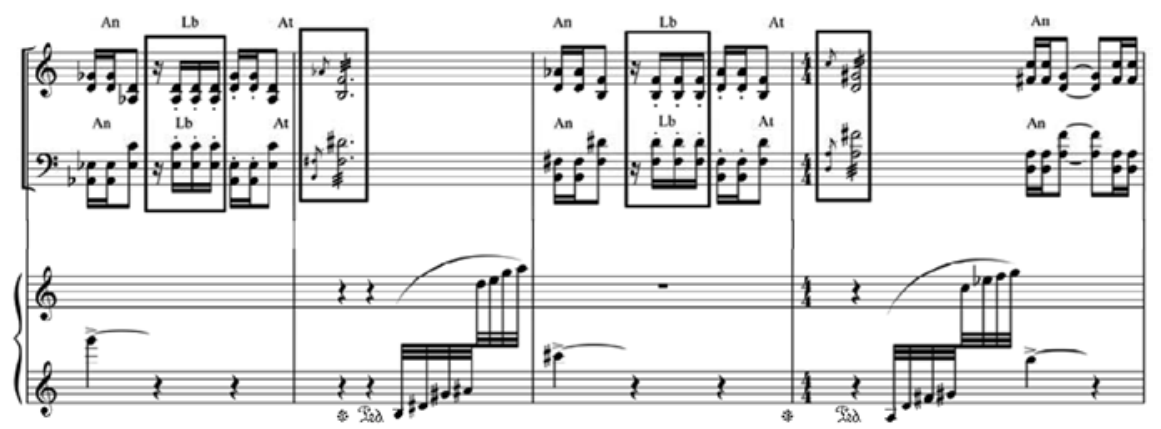

34 Secuencias similares son observadas en algunas obras posteriores de Garrido-Lecca como Preludio y tocata (1988), Dúo concertante (1991) y Soliloquio I (1992).

35 Para poder apreciar el "acorde místico" de Garrido-Lecca en los primeros pulsos de los compases 124 y 126, las acciaccaturas no deben ser consideradas. 
La última cadenza es interpretada por el violín y el violonchelo; se inicia con una versión del "acorde místico" (La-Sol\#-Fa\#-Re) que es ejecutado con la participación de ambos instrumentos. Luego de este acorde el violín presenta un solo de manera libre, que denota un claro tratamiento polifónico del instrumento ${ }^{36}$. En la primera parte de la cadenza el compositor usualmente utiliza dobles y triples cuerdas en el violín, mientras que el uso de las cuatro cuerdas es reservado para la aparición del "acorde místico", lo que se verifica en el segundo sistema de la cadenza. Esta particular presentación del acorde por parte del violín solo está conformada por dos de sus cuerdas abiertas (Sol-Re) y dos pulsadas (Do\# y Si).

En el tercer sistema de la cadenza aparece el violonchelo, instrumento que muestra un tratamiento también polifónico con el uso de dobles, triples y cuádruples cuerdas. Al igual que en el caso del violín, el violonchelo presenta una versión del "acorde místico" por medio de dos de sus cuerdas abiertas (Do-Sol) y dos pulsadas (Fa\# y Mi). Finalmente en un registro agudo y con una dinámica fortissimo enfatizada por acentos, ambos instrumentos de cuerda presentan el "acorde místico" tres veces, esta vez conformado por las alturas Sol-Fa\#-Mi-Do (ver ejemplo 25).

Ejemplo 25. Trío para un nuevo tiempo, tercer movimiento, c.127 (cadenza).
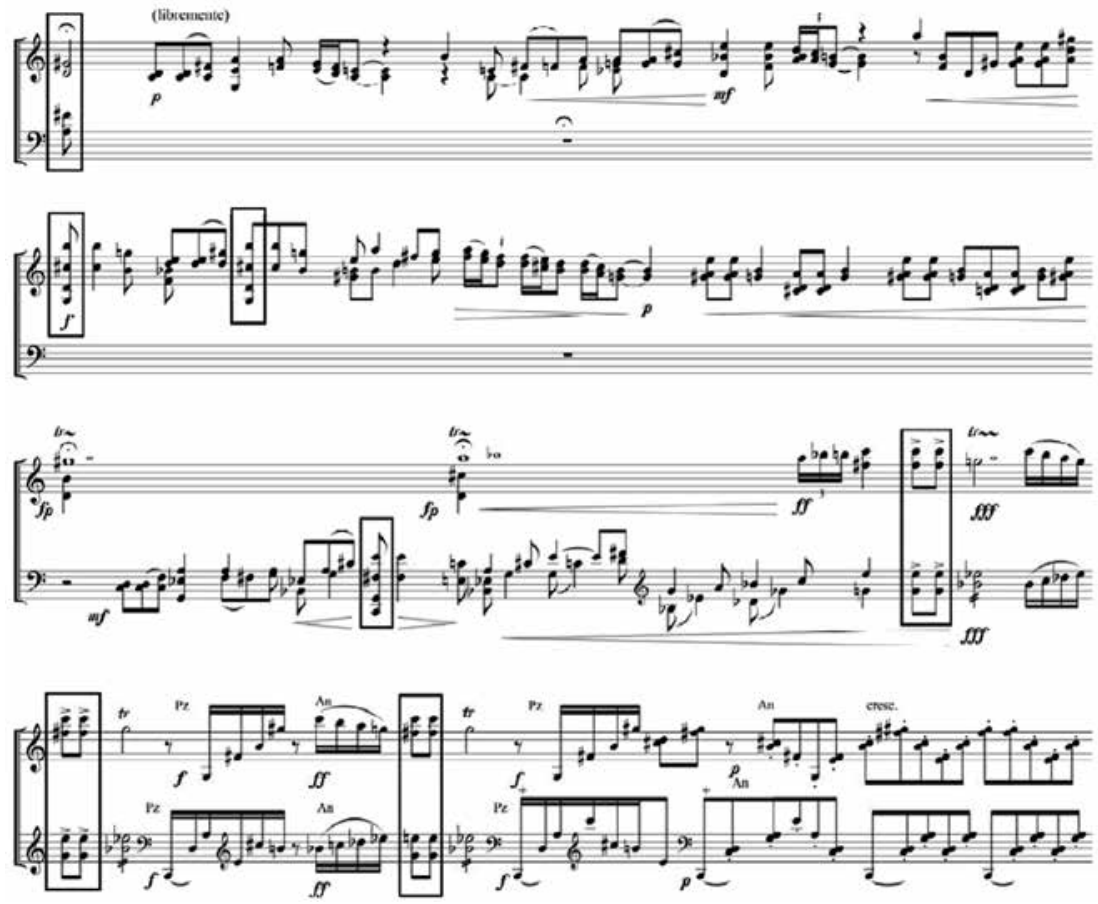

36 Un elemento característico de la tercera fase compositiva de Garrido-Lecca es la textura polifónica que obtiene de los instrumentos de cuerda frotada, al combinar cuerdas abiertas y pulsadas en la producción de determinados acordes. 
La melodía pentatónica anhemitónica, presentada anteriormente por el violín entre los compases 41 y 55 , es repetida por este mismo instrumento a partir del compás 161. Esta nueva presentación está ornamentada por pequeñas notas en forma de arpegios ascendentes y es enfatizada mediante el uso del registro agudo del instrumento, un tempo más lento, cambio de metro y dinámicas fortissimo (ver ejemplo 26).

Ejemplo 26. Trío para un nuevo tiempo, tercer movimiento, cc.161-172 (violín).

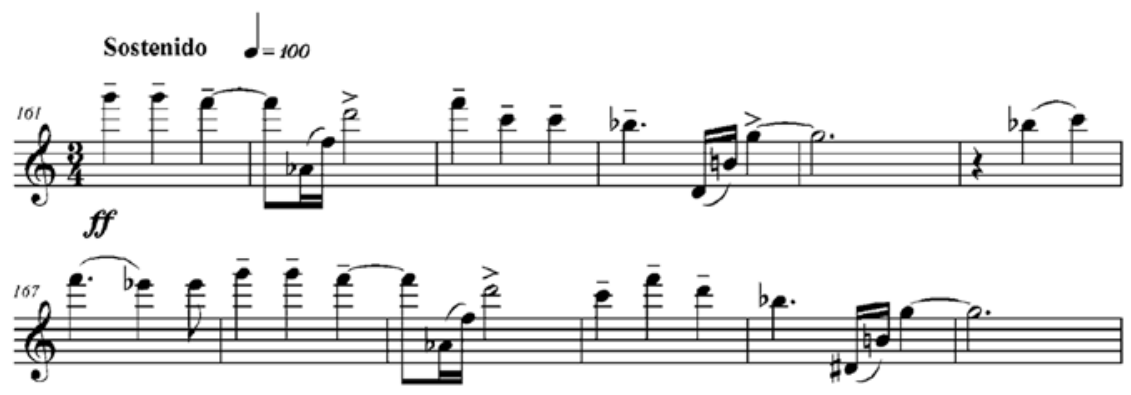

El piano acompaña esta melodía pentatónica con varias versiones del "acorde místico”, que se inician en el segundo pulso del compás 161 con una versión simple de este en dos octavas diferentes, sobre los sonidos Sol\#-Sol-Fa-Do\# (ver ejemplo 27).

Ejemplo 27. Trío para un nuevo tiempo, tercer movimiento, cc.157-161.

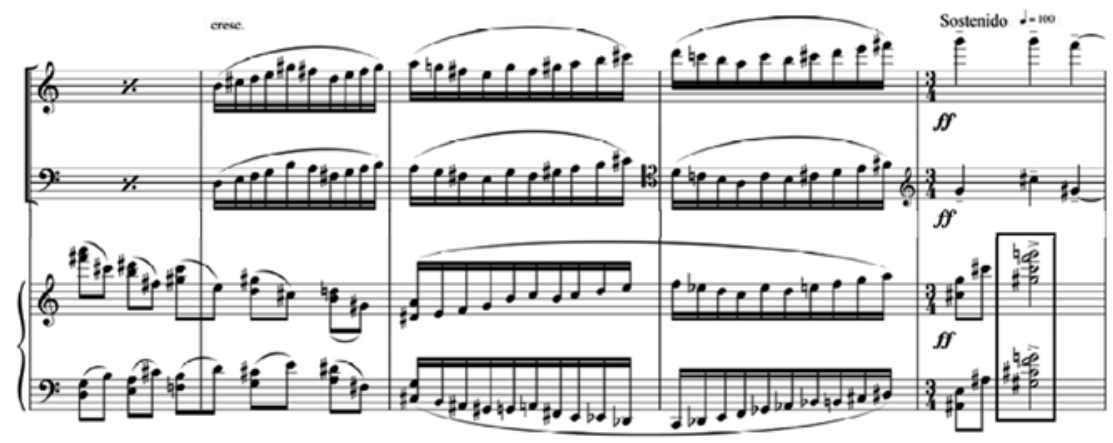

Finalmente, el violonchelo repite en su registro medio esta melodía andina entre los compases 174 y 182 (ver ejemplo 28).

Ejemplo 28. Trío para un nuevo tiempo, tercer movimiento, cc.174-182 (violonchelo).

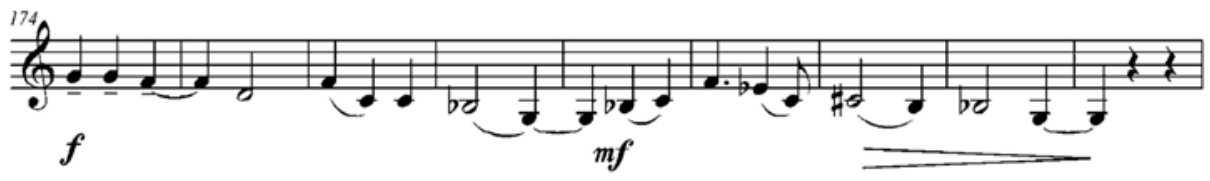


Trío para un nuevo tiempo finaliza con dos importantes elementos musicales que el compositor continuará explorando en sus obras posteriores: su "acorde místico" y el tritono. Los últimos cinco compases del piano son particularmente gráficos en este aspecto pues muestran la alternancia de ambos elementos: un tritono formado por La y Mib, y un "acorde místico" que se forma con los sonidos adicionales Sol y Sib, el cual es ejecutado simultáneamente por ambas manos (ver ejemplo 29).

Ejemplo 29. Trío para un nuevo tiempo, tercer movimiento, cc.199-203.

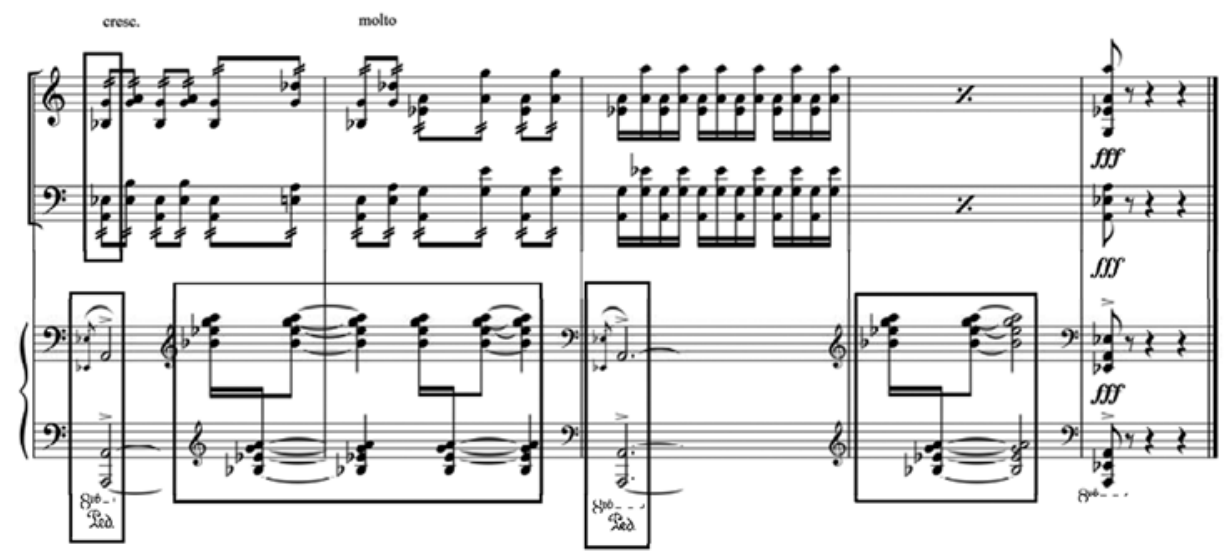

Trío para un nuevo tiempo fue encargado por el Trío Arte de la Pontificia Universidad Católica de Chile, una agrupación musical formada entonces por Sergio Prieto (violín), Edgar Fischer (violonchelo) y María Iris Radrigán (piano). Fue estrenado por este trío clásico en Lima en 1987. Obtuvo el primer premio en la categoría "música de cámara" de un concurso convocado por la Sociedad Filarmónica de dicha ciudad ${ }^{37}$. El 8 de agosto de 1995, durante una temporada de conciertos organizada por la Escuela Moderna de Música, Trío para un nuevo tiempo fue ejecutado en Santiago de Chile por Lina Bahn (violín), Pablo Mahave (violonchelo) y Eduardo Browne (piano) en la Sala Elena Waiss ${ }^{38}$. De acuerdo con un aviso promocional publicado el 7 de enero de 1996 en The New York Times, el estreno de esta pieza en Estados Unidos ocurrió el 24 de enero de 1996 en el Teatro Juilliard de Nueva York, durante una temporada de conciertos titulada "Around the Rim: Music of the Pacific Nations". El 16 de junio de 1996 Trio para un nuevo tiempo fue interpretado en el Centro Reina Sofía de Madrid, España, por el Grupo Neos ${ }^{39}$.

\footnotetext{
37 Tello 2001b: 30.

38 Ver "Otras salas", RMCh, XLIX/184 (julio-diciembre, 1995), p. 109.

39 Ver "Noticias de Celso Garrido-Lecca", RMCh, L/186 (julio-diciembre, 1996), p. 93.
} 


\section{CONCLUSIONES}

Trío para un nuevo tiempo (1985) es una de las composiciones más significativas en la obra creativa de Celso Garrido-Lecca pues marca el comienzo de su tercera etapa compositiva y define las principales características musicales que su obra exhibirá a partir de 1985. Mediante el análisis que se ha realizado fue posible identificar un sincretismo de materiales musicales provenientes de diferentes tradiciones culturales, lo cual ha sido justamente uno de los principales objetivos del compositor en su tercera fase.

El llamado "acorde místico" de Garrido-Lecca juega ciertamente un rol central en esta composición, como uno de sus principales soportes armónicos. Aunque este acorde figura de manera prominente en el tercer movimiento, especialmente a partir del compás 92, está permanentemente presente en los dos movimientos previos mediante sus dos díadas constituyentes: la tercera menor y el tritono. La tercera menor está usualmente representada en esta obra por las alturas Sol-Sib, mientras que el tritono se representa mediante la díada La-Mib.

Garrido-Lecca escogió una conocida y simbólica canción de Violeta Parra, Gracias a la vida, como principal fuente de material para el movimiento central. Sin duda el compositor desea demostrar con ello su conexión ideológica, musical y emocional con el movimiento de la Nueva Canción. Garrido-Lecca no solo reconoce el simbolismo que adquiere el intervalo de tritono en Gracias a la vida (1966), sino que además adopta este intervalo como un elemento característico de su propia producción después de 1985. En directa conexión con el significado que hemos asignado al intervalo de tritono en la canción Los pueblos americanos de Violeta Parra, nos atrevemos a proponer que en el caso de Garrido-Lecca este intervalo pueda ser también una representación musical de la inestabilidad social, económica y política de América Latina ${ }^{40}$.

La incorporación de elementos musicales provenientes de la tradición andina constituye otra característica importante del tercer período compositivo de GarridoLecca. Diversos elementos de esta tradición pueden ser observados en esta obra y en otras piezas posteriores. Estos incluyen el uso de ornamentos melódicos en forma de acciaccaturas, la presentación simultánea de los instrumentos en sus registros más agudos, el movimiento descendente de muchas melodías, la presencia de ritmos sincopados y de "terceras arequipeñas", el uso de escalas pentatónicas anhemitónicas y una preferencia estética por el intervalo de tercera menor.

En el Trio para un nuevo tiempo (1985) se advierten también elementos musicales fuertemente entroncados con la tradición occidental. Estos elementos incluyen un ensamble clásico constituido por un violín, un violonchelo y un piano, una notación musical diastemática convencional, formas tripartitas y cadenzas, por nombrar solo algunos. Con relación al lenguaje musical del siglo XX figuran motivos basados en las doce alturas del sistema musical occidental, la utilización

40 La canción Los pueblos americanos fue citada por Garrido-Lecca en el cuarto movimiento de su Cuarteto de Cuerdas $\mathrm{N}^{\circ} 3$ (1991). Esta interpretación que hemos dado al intervalo de tritono ha sido compartida por el compositor. 
de técnicas extendidas en los tres instrumentos musicales y la heterometría. El estilo de Garrido-Lecca posterior a 1985 se caracteriza también por el tratamiento polifónico de los instrumentos de cuerda frotada, por su predilección hacia los sonidos armónicos y por el establecimiento de ostinatos o notas pedales que se prolongan por varios compases, elementos que están claramente identificados en el Trío para un nuevo tiempo.

Los tres movimientos de esta composición deben ser ejecutados sin interrupción y el movimiento central se distingue de los dos extremos por presentar elementos musicales exclusivos y diferenciadores. Esta conformación es verificable también en otras obras de Garrido-Lecca, antes y después de 1985. Está asociada con el concepto de "tiempo circular" que el compositor dice haber absorbido de su contacto temprano con filosofías orientales ancestrales. Intihuatana, pieza para cuarteto de cuerdas de 1967, es la primera obra que presenta esta idea cíclica por medio de su estructura palindrómica ${ }^{41}$. Este concepto alcanzará su punto más álgido en la segunda Sinfonía de Garrido-Lecca subtitulada "Introspecciones" de 1999-200042, la que está basada en un poema de Jorge Luis Borges que aborda esta misma temática.

\section{BIBLIOGRAFÍA}

\section{Publicaciones impresas}

Béhague, Gerard

1979 Music in Latin America: an Introduction. Nueva Jersey: Prentice Hall.

D'Harcourt, Raoúl y Marguerite D'Harcourt

1990 La música de los Incas y sus supervivencias. Traducción de Roberto Miró Quesada. Lima: Occidental Petroleum Corporation of Peru.

García, Susana

2000 "Scriabin's Symbolist Plot Archetype in the Late Piano Sonatas", 19th-Century Music, XXIII/3 (primavera), pp. 273-300.

41 La estructura palindrómica de Intihuatana tiene probablemente como su principal modelo al Concierto de Cámara de Alban Berg, obra compuesta en 1925 para violín y piano con acompañamiento de trece instrumentos de viento. De acuerdo con la información proporcionada por el propio Berg por medio de una carta abierta publicada en la revista Pult und Taktstock de febrero de 1925, la obra presenta elementos que aparecen simbólicamente agrupados de a tres, en referencia al triunvirato de compositores asociados a la Segunda Escuela de Viena. En esta obra es posible advertir una utilización libre del sistema dodecafónico, mientras que su estructura está organizada de manera simétrica a través de prominentes palíndromes seccionales, inversiones y retrogradaciones, conjuntamente con la utilización de estructuras clásicas como sonata, tema con variaciones, formas ternarias y rondó. También se advierten elementos programáticos vinculados a aspectos personales del compositor, los cuales son expresados de manera simbólica mediante la utilización de números y de temas musicales que asocian determinados nombres con la nomenclatura alfabética musical alemana. Ver Simms 2014: 281.

42 Esta es la fecha de composición señalada en Garrido-Lecca 2008:6. Por el contrario Tello 2001b:32 indica que la Sinfoní $\mathrm{N}^{\circ} 2$ fue compuesta entre 1996 y 1997. Se ha preferido la fecha 19992000 , toda vez que ha sido confirmada por escrito por el mismo compositor. 
Garrido-Lecca, Celso

2000 Trío para un nuevo tiempo. Lima: Biblioteca Nacional del Perú.

2008 Celso Garrido-Lecca. Premio iberoamericano de la música 2000 Tomás Luis de Victoria. Notas al disco compacto. Madrid: Sociedad General de Autores y Editores (SGAE) y Fundación Autor, Sello Autor (SA01455).

González, Juan Pablo

2006 "Migración amorosa y musical en 'Run Run se fue pa'l norte' de Violeta Parra", Ensayos: Historia y Teoría del Arte, $\mathrm{N}^{\circ} 11$. Bogotá: Instituto de Investigaciones Estéticas (IIE) de la Facultad de Artes de la Universidad Nacional de Colombia, pp. 173-186.

ITURRIAGA, ENRIQUE

2001 "Garrido-Lecca (Seminario), Celso", The New Grove Dictionary of Music and Musicians. Segunda edición. Editado por Stanley Sadie y John Tyrrell. Tomo IX. Londres: Macmillan, pp. 549-550.

Merino Montero, Luis

2003 “1973-2003: treinta años”, RMCh, LVII/199 (enero-junio), pp. 39-56.

Morgan, Robert P.

1990 Twentieth-Century Music: A History of Musical Style in Modern Europe and America. Nueva York: Norton \& Company.

NANDORFY, MARTHA

2003 The Right to Live in Peace: Freedom and Social Justice in the Songs of Violeta Parra and Victor Jara [Rebel Musics: Human Rights, Resistant Sounds, and the Politics of Music Making, editado por Daniel Fischlin y Ajay Heble]. Montreal, Canadá: Black Rose Books.

Niño VÁsQUez, NeLson

2011 Celso Garrido-Lecca: Synthesis and Syncretism in Concert Music of the Andes Area. Tesis doctoral. Washington, D.C.: The Catholic University of America. Profesor guía: Dr. George Grayson Wagstaff. Publicada en el archivo digital ProQuest. (http:// www.proquest.com/products-services/dissertations/)

Oporto VAlencia, Lucy

2007 El diablo en la música. La muerte del amor en El gavilán, de Violeta Parra. Viña del Mar: Ediciones Altazor.

Pople, Anthony

1998 Messiaen. Quatuor pour la fin du temps. Cambridge: Cambridge University Press.

Rischin, REBECCA

2003 For the End of Time. The Story of the Messiaen Quartet Updated with New Material. Nueva York: Cornell University Press.

Sáez, Fernando

1999 La vida intranquila: Violeta Parra, biografía esencial. Santiago: Editorial Sudamericana.

Santa Cruz Wilson, Domingo

2007 Mi vida en la música. Contribución al estudio de la vida musical chilena durante el siglo XX. Edición y revisión musicológica por Raquel Bustos Valderrama. Santiago: Ediciones Universidad Católica de Chile, Consejo Nacional de la Cultura y las Artes, Consejo Nacional del Libro y la Lectura. 
SimMs, BRYAN R.

2014 Pro Mundo Pro Domo: The Writings of Alban Berg. Nueva York: Oxford University Press.

Tello, Aurelio

2001a "Antaras de Celso Garrido-Lecca o la perenne persistencia de la peruanidad", $R M C h, \mathrm{LV} / 196$ (julio-diciembre), pp. 7-26.

2001b "Catálogo de las obras musicales de Celso Garrido-Lecca”, RMCh, LV/196 (juliodiciembre), pp. 27-32.

Torres Alvarado, Rodrigo

1999 “Garrido-Lecca, Celso", Diccionario de la Música Española e Hispanoamericana. Volumen 5. Director y coordinador general: Emilio Casares Rodicio. Madrid: SGAE (Sociedad General de Autores y Editores), pp. 525-528.

\section{Fuentes manuscritas}

\section{Advis, Luis y Violeta Parra}

1972 Canto para una semilla. Partitura manuscrita. 